This article was downloaded by: [Domingues, Ana Patrícia]

On: 29 April 2009

Access details: Access Details: [subscription number 910815050]

Publisher Informa Healthcare

Informa Ltd Registered in England and Wales Registered Number: 1072954 Registered office: Mortimer House, 37-41 Mortimer Street, London W1T 3JH, UK

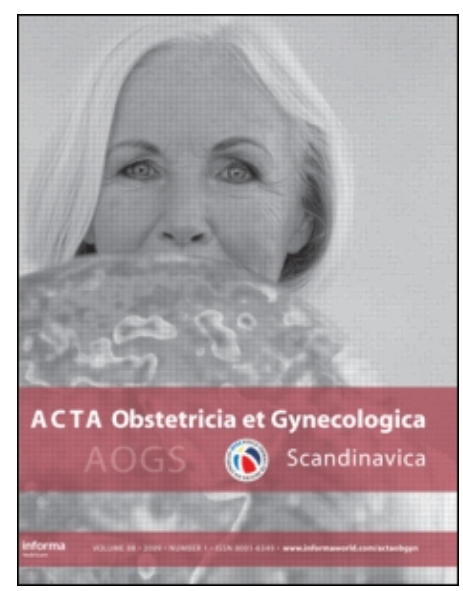

\title{
Acta Obstetricia et Gynecologica Scandinavica
}

Publication details, including instructions for authors and subscription information:

http://www.informaworld.com/smpp/title content=t716100748

\section{Endometrial polyps in postmenopausal women}

Ana Patrícia Domingues a; Helena Lopes a; Isabel Dias a; Carlos Freire De Oliveira ab

a Department of Gynecology, Coimbra University Hospitals, Coimbra, Portugal ${ }^{b}$ Gynecological Clinic of the Faculty of Medicine, Coimbra University, Coimbra, Portugal

First Published:2009

To cite this Article Domingues, Ana Patrícia, Lopes, Helena, Dias, Isabel and De Oliveira, Carlos Freire(2009)'Endometrial polyps in postmenopausal women',Acta Obstetricia et Gynecologica Scandinavica,88:5,618 - 620

To link to this Article: DOI: $10.1080 / 00016340902818188$

URL: http://dx.doi.org/10.1080/00016340902818188

\section{PLEASE SCROLL DOWN FOR ARTICLE}

\footnotetext{
Full terms and conditions of use: http://www.informaworld.com/terms-and-conditions-of-access.pdf

This article may be used for research, teaching and private study purposes. Any substantial or systematic reproduction, re-distribution, re-selling, loan or sub-licensing, systematic supply or distribution in any form to anyone is expressly forbidden.

The publisher does not give any warranty express or implied or make any representation that the contents will be complete or accurate or up to date. The accuracy of any instructions, formulae and drug doses should be independently verified with primary sources. The publisher shall not be liable for any loss, actions, claims, proceedings, demand or costs or damages whatsoever or howsoever caused arising directly or indirectly in connection with or arising out of the use of this material.
} 


\title{
Endometrial polyps in postmenopausal women
}

\author{
ANA PATRÍCIA DOMINGUES ${ }^{1}$, HELENA LOPES ${ }^{1}$, ISABEL DIAS ${ }^{1}$ \& CARLOS FREIRE \\ DE OLIVEIRA ${ }^{1,2}$ \\ ${ }^{1}$ Department of Gynecology, Coimbra University Hospitals, Coimbra, Portugal, and ${ }^{2}$ Gynecological Clinic of the Faculty of \\ Medicine, Coimbra University, Coimbra, Portugal
}

\begin{abstract}
The malignancy risk of endometrial polyps in postmenopausal women was correlated with the presence or absence of abnormal uterine bleeding. Of 481 postmenopausal women who presented with endometrial polyps at diagnostic hysteroscopy between 2004 and 2007, 48.9\% were asymptomatic and $51.1 \%$ had postmenopausal uterine bleeding. Transvaginal ultrasound revealed abnormal endometrial thickness in $60.0 \%$ vs. $57.7 \%$, polyps in $37.9 \%$ vs. $32.9 \%$, endometrial tumors in $1.3 \%$ vs. $0.8 \%$, and submucosal myomas in $0.9 \%$ vs. $2.0 \%$ by the absence or presence of bleeding. Around three-fourth of the polyps were removed. Histopathologic diagnoses showed mucous polyps in 93.7 of asymptomatic women compared to $80.7 \%$ of those with bleeding, while endometrial tumors were only seen in those bleeding $(7.2 \%)$. The malignancy risk within endometrial polyps in postmenopausal women varies with the presence of vaginal bleeding, and is minimal in asymptomatic women.
\end{abstract}

Key words: Endometrial polyps, postmenopausal women, postmenopausal bleeding, endometrial cancer

\section{Introduction}

The introduction of transvaginal ultrasound in routine gynecological practice has increased the number of asymptomatic lesions identified in postmenopausal women (1-4). The prevalence of endometrial polyps is unknown because they frequently occur without associated symptomatology, but in women with abnormal bleeding, it has been reported to range from $13 \%$ to $50 \%$ (3). Even though most lesions are benign, some are premalignant (simple or complex hyperplasia with cytological atypia) or malignant (endometrial cancer) (2). Although the malignancy potential of endometrial polyps is uncertain, they are believed to be a risk factor for endometrial cancer and the actual incidence of malignancy detected in endometrial polyps has ranged between $0.5 \%$ and $4.8 \%$ $(1,4)$. The entire suspicious lesion can be removed under direct vision by hysteroscopic polypectomy, which is generally regarded as the 'gold standard' for the diagnosis of polyps $(2,4)$ and recommended for symptomatic patients. A similar approach is reasonable for asymptomatic polyps in postmenopausal women to disprove a malignant condition, although this procedure is arguable $(1,3,4)$.

The objective of this study was to evaluate the risk of malignancy of endometrial polyps in postmenopausal women according to the presence or absence of symptomatology.

\section{Material and methods}

From the Departmental hysteroscopy database, we selected all 481 postmenopausal women who underwent a diagnostic hysteroscopy between 2004 and 2007 and were diagnosed with endometrial polyps. We considered postmenopausal women older than 40 years who had cessation of menstrual period more than 12 months before, and abnormal uterine bleeding was considered to be any uterine bleeding thereafter.

Correspondence: Ana Patrícia Rodrigues Domingues, Serviço de Ginecologia, Hospitais da Universidade de Coimbra, Praceta Dr. Mota Pinto, 3004-561 Coimbra, Portugal. E-mail: anapatriciadomingues@hotmail.com 
All patients were referred for diagnostic hysteroscopy because of abnormal uterine bleeding or an abnormal transvaginal ultrasound finding. The women were considered in two groups: those with episodes of postmenopausal bleeding and those asymptomatic. From the medical records, data were collected on age, menopausal age, use of hormonal therapy, and medical conditions associated with endometrial cancer risk (hypertension, diabetes). Transvaginal ultrasound findings before hysteroscopy were evaluated for both groups.

Operative hysteroscopy was proposed to all patients, usually as an ambulatory procedure; but when not possible/tolerated/accepted by the patient, a surgical hysteroscopy was done under general anesthesia, using a $9 \mathrm{mM}$ Storz resectoscope. The identified lesion was completely removed. Histological results in both groups were compared.

The data were analyzed using SPSS version 15.0, with chi-squared test for qualitative and the $t$-test for quantitative variables. A value of $p<0.05$ was considered significant. Logistic regression analysis was used to determine adjusted odds ratios and 95\% confidence intervals of abnormal uterine bleeding, hormonal therapy use, hypertension, and diabetes on tumor incidence.

\section{Results}

Of the women, $48.9 \%$ were asymptomatic and $51.1 \%$ had postmenopausal uterine bleeding. Mean age at diagnosis was (asymptomatic vs. symptomatic)
$63.1 \pm 8.3$ vs. $62.7 \pm 9.7$ years and menopausal mean age $50.0 \pm 4.2$ vs. $49.6 \pm 4.4$ years. Of the women, $15.2 \%$ vs. $17.7 \%$ had hypertension and $4.4 \%$ vs. $4.2 \%$ had diabetes, a non-significant difference. Hormonal therapy was used by $5.6 \%$ of the asymptomatic women and by $11 \%$ of those symptomatic $(p=0.001)$. The pre-treatment transvaginal ultrasound findings are summarized in Table I. Diagnosed polyps were surgically removed in, respectively, $74.5 \%$ vs. $73.6 \%$ of the women. In the remaining cases, removal was either performed outside our department or refused by the patients.

The histopathologic results of the removed polyps (Table I) revealed mucous polyps in $93.7 \%$ of the asymptomatic women and $80.7 \%$ of those bleeding. Endometrial tumor material was only noted in the symptomatic group $(7.2 \% ; p<0.0001)$, and cytological atypia was also more frequent in this group $(2.2 \%, p=0.021)$. Logistic regression analysis showed a significant increase $(p<0.0001)$ in the incidence of malignancy in the polyps of women who presented with abnormal uterine bleeding (when compared to asymptomatic group), but no significant influence of hormone replacement therapy (HRT) $(p=0.247$; OR $0.34,95 \%$ CI: $0.04-2.65)$, hypertension ( $p=0.367$; OR 1.37 , 95\% CI: $0.49-$ $3.86)$ or diabetes $(p=0.414$; OR $1.54,95 \% \mathrm{CI}$ : $0.33-7.13)$. For the incidence of pre-malignancy in polyps, analysis also showed significant influence of postmenopausal bleeding ( $p=0.021$; OR $8.05,95 \%$ CI: $0.99-65.02)$, but no significant influence of HRT $(p=0.535$; OR $0.61,95 \%$ CI: $0.08-4.97)$,

Table I. Overview of the results obtained according to the presence of uterine bleeding.

\begin{tabular}{|c|c|c|c|c|c|}
\hline \multirow[b]{2}{*}{$N=481$} & \multicolumn{2}{|c|}{ Asymptomatic } & \multicolumn{2}{|c|}{ Symptomatic } & \multirow[t]{2}{*}{$p$} \\
\hline & 235 & $48.9 \%$ & 246 & $51.1 \%$ & \\
\hline $\begin{array}{l}\text { Transvaginal ultrasound } \\
\text { Endometrial thickness } \\
\text { Polyp } \\
\text { Endometrial tumor } \\
\text { Submucousal myoma }\end{array}$ & $\begin{array}{r}141 \\
89 \\
3 \\
2\end{array}$ & $\begin{array}{r}60.0 \% \\
37.9 \% \\
1.3 \% \\
0.9 \%\end{array}$ & $\begin{array}{r}142 \\
81 \\
2 \\
5\end{array}$ & $\begin{array}{r}57.7 \% \\
32.9 \% \\
0.8 \% \\
2.0 \%\end{array}$ & \\
\hline Polypectomy & 175 & $74.5 \%$ & 181 & $73.6 \%$ & \\
\hline $\begin{array}{l}\text { Histopathologic results } \\
\text { Mucous polyps } \\
\text { Endometrial tumors }\end{array}$ & $\begin{array}{r}164 \\
0\end{array}$ & $\begin{array}{c}93.7 \% \\
0 \%\end{array}$ & $\begin{array}{r}146 \\
13\end{array}$ & $\begin{array}{r}80.7 \% \\
7.2 \%\end{array}$ & $<0.0001$ \\
\hline $\begin{array}{l}\text { Cystic hyperplasia } \\
\text { Complex } \\
\text { Simple } \\
\text { With cytological atypia } \\
\text { Normal endometrium } \\
\text { Cystic atrophy of the endometrium } \\
\text { Atrophic endometrium } \\
\text { Submucousal myoma }\end{array}$ & $\begin{array}{l}1 \\
1 \\
1 \\
3 \\
2 \\
2 \\
1\end{array}$ & $\begin{array}{l}0.6 \% \\
0.6 \% \\
0.6 \% \\
1.7 \% \\
1.1 \% \\
1.1 \% \\
0.6 \%\end{array}$ & $\begin{array}{l}1 \\
8 \\
8 \\
1 \\
1 \\
2 \\
4\end{array}$ & $\begin{array}{l}0.6 \% \\
4.4 \% \\
4.4 \% \\
0.6 \% \\
0.6 \% \\
1.1 \% \\
2.2 \%\end{array}$ & 0.021 \\
\hline
\end{tabular}


hypertension $(p=0.499$; OR $0.77,95 \%$ CI: 0.19 $3.21)$, or diabetes $(p=0.199$; OR $2.91,95 \%$ CI: $0.58-14.63)$.

\section{Discussion}

The rate of malignancy in endometrial polyps, i.e. 13 cases or $2.7 \%$ of the total study population, was within the range reported of $0.8-4.8 \%$ (3-6). Although uterine bleeding as a predictive factor for malignancy in endometrial polyps has not been universally reported (4), and risk of pre-malignancy and malignancy within endometrial polyps in postmenopausal women differed, in our study similar to others the risk was significantly higher in the symptomatic group with the presence of vaginal bleeding $(3,5,7)$.

We also observed that the risk of a pre-malignant or malignant lesion in a polyp was not affected by use of HRT or by the presence of others risks factors for malignancy, such as hypertension or diabetes, consistent with other authors $(4,5)$. Considering this, operative hysteroscopy with complete removal of the polyp (a safe procedure in this age group) should be offered to all symptomatic patients, regardless of the presence or absence of risk factors $(1,2,5)$.

The evaluation of polyps in asymptomatic women may allow the detection of pre-malignant conditions and an earlier diagnosis of endometrial carcinoma (1). The presence of malignancy in extracted polyps of this group of women was reported in one large study, but it included a heterogeneous population of pre- and postmenopausal patients $(1,5)$. A decision to remove asymptomatic polyps in postmenopausal women must take into consideration certain factors like the inherent risk of malignancy or pre-malignant pathology, the potential malignant transformation of benign incidental polyps over the years if left in situ and the risks of the procedure itself (1).
In women with a high operative risk, conservative management may be a safe option $(1,2,4)$. The results of this study suggest that in asymptomatic postmenopausal women with endometrial polyps confirmed by hysteroscopy, in whom ambulatory or programmed operative hysteroscopy is not possible, transvaginal ultrasound or diagnostic hysteroscopy in a regular surveillance scheme are alternative options to surgery, being a safe procedure and reducing surgical morbidity.

Disclosure of interests: The authors report no conflicts of interest. The authors alone are responsible for the content and writing of the paper.

\section{References}

1. Lev-Sagie A, Hamani Y, Imbar T, Hurwitz A, Lavy Y. The significance of intrauterine lesions detected by ultrasound in asymptomatic postmenopausal patients. BJOG. 2005;112: 379-81.

2. Machtinger R, Korach J, Padoa A, Fridman E, Zolti M, Segal J et al. Transvaginal ultrasound and diagnostic hysteroscopy as a predictor of endometrial polyps: risk factors for premalignancy and malignancy. Int J Gynecol Cancer. 2005;15:325-8.

3. Lieng M, Qvigstad E, Sandvik L, Jørgensen H, Langebrekke A, Istre O. Hysteroscopic resection of symptomatic and asymptomatic endometrial polyps. J Minim Invasive Gynecol. 2007;14: 189-94.

4. Antunes A Jr, Costa-Paiva L, Arthuso M, Costa JV, Pinto-Neto AM. Endometrial polyps in pre- and postmenopausal women: factors associated with malignancy. Maturitas. 2007;57: 415-21.

5. Savelli L, De Iaco P, Santini D, Rosati F, Ghi T, Pignotti E et al. Histopathologic features and risk factors for benignity, hyperplasia and cancer in endometrial polyps. Am J Obstet Gynecol. 2003;188:927-31.

6. Goldstein SR, Monteagudo A, Popiolek D, Mayberry P, Timor-Tritsch I. Evaluation of endometrial polyps. Am J Obstet Gynecol. 2002;186:669-74.

7. Orvieto R, Bar-Hava I, Dicker D, Bar J, Ben-Rafael Z, Neri A. Endometrial polyps during menopause: characterization and significance. Acta Obstet Gynecol Scand. 1999;78:883-6. 